\title{
Properties of Mixed Polypropylene / Polylactide after Multiple Processing
}

\author{
Mariusz Fabijański ${ }^{1 *}$, Jacek Garbarski ${ }^{2}$ \\ 1 Polymer Processing Department, Faculty of Production Engineering, Warsaw University of Technology, \\ Narbutta 85, 02-524 Warsaw, e-mial: mfabijan@wip.pw.edu.pl. \\ 2 Polymer Processing Department, Faculty of Production Engineering, Warsaw University of Technology, \\ Narbutta 85, 02-524 Warsaw, e-mial: garbarski@wp.pl. \\ * Correspondence: e-mail: e-mail:mfabijan@wip.pw.edu.pl
}

\begin{abstract}
Polypropylene (PP) is commonly used in the polymer processing industry. Its feature is a good chemical resistance, it is non-toxic and not harmful to people. Polypropylene is widely used in the manufacturing of food packages, laboratory and medical equipment, electric cables insulators, automotive parts, toys and furniture. The application of this material enables us to obtain complicated shapes of big surfaces. It is also highly recyclable. Polylactide (PLA) is a product of the so called "green chemistry" because it is obtained from the renewable raw materials (biomass). As its price is higher compared to the traditional polymers, its repeated use (recycling) is of high interest. Due to the same reason (cost) the mixtures of PLA with other polymers are applied. In this paper the results of testing the PP/PLA mixtures of various mass ratio of the components are presented. Technical terms of preparing and processing such mixtures have been practically tested. Also the mechanical strength was determined based on the static tensile tests. The results showed that those mixtures can be repeatedly processed. Even five-times reprocessing does not cause essential drop of mechanical properties
\end{abstract}

Keywords: polylactide, polypropylene, polymer mixtures, mechanical strength, recycling

\section{Introduction}

Developing new polymers is more and more difficult and expensive. That is why mixtures are an alternative group of new materials of unique properties. The trend is to obtain a new material of the desired mechanical properties and general good quality by inexpensive methods. Compositions of polymers are obtained which theoretically do not create a stable mixture (components are mutually unmissable) [1,2]. The ratio of the components is selected in such a way that a standard processing would be possible. The physical mixing of polymers is done which results in obtaining a material in which one of the polymers is a matrix and the other is a filler [3].

Physical modification means changing polymer structure caused by imposed orientation, mixing the polymer (matrix) with the additives, changing the dispersion degree of the phases constituting the material and changing the form and the size of the interphase zone. Physical modification means also changing the molecular interaction between the phases as a result of adding the mixing compatibilizers which have an influence on the matrix microstructure and are often active in the chemical reaction with the other components of the mixture. That is why it is often difficult to recognize which modification is physical and which is chemical as the chemical one often incorporates block, statistical and graft copolymerization as well as changing the molecular weight, macromolecular structure, crosslinking etc. [4,5].

Polymer mixtures can be subdivided into physical mixtures graft and block copolymers and the systems of mutually penetrating crosslinked structures. The common feature of all polymer mixture is presence of the polymeric matrix in which all the other components are dispersed. The properties of polymer mixture depend on its content, the way it was prepared and the components interactions. All these factors are decisive in terms of the structure of the obtained mixture. 
Depending on the dispersion degree of the components and on their physical/chemical properties the solutions or the colloid systems can be obtained. The reasons of the non-homogenous properties of the polymer mixture can be the thermodynamic non-miscibility or a substantial difference of the components viscosity which blocks building a homogenous structure even in case of the thermodynamic miscibility [6, 7].

The thermodynamic measure of polymer miscibility is the decrease of the free energy of the system at its constant volume $(\Delta F<0)$ or the decrease of its free enthalpy $(\Delta G m>0)$ at the constant pressure. It is the necessary condition, however the additional, following condition must be fulfilled as well (1):

$$
\left(\left(\mathrm{d}^{2} \Delta \mathrm{Gm}\right) /\left(\mathrm{dx} \mathrm{x}^{2}\right)\right)_{\mathrm{p}, \mathrm{T}}>0
$$

where: $x$ is the volumetric ratio of the component of the mixture.

The change of the free enthalpy of the system is determined by the change of the enthalpy $\Delta \mathrm{Hm}$ and the entropy $\Delta S m$ according to the equation (2):

$$
\Delta G m=\Delta H m-T \Delta S m
$$

The so defined change of the entropy being the result of the component dispersion in the polymeric matrix has positive values. It would favor forming the solution but in the ambient temperature the influence of the entropy is minimal. Enthalpy is much more meaningful for the miscibility of polymeric systems. Its change is dependent on the interaction of the mixture components. If in the mixing process heat is generated, it means that such components are miscible in the full range of concentrations. For most polymers, however, the thermal effect of mixing is negative or close to zero $[7,8,9]$.

The mixing enthalpy is determined as the relation of interaction energy of two different components $A$ and $B$ to the interaction energy between the macromolecules of the same polymers. In the literature the most frequent factors characterizing macromolecular interaction are the Hildebrand parameters of solubility $\delta$ or the Flory-Huggins coefficient defined as $(\chi A B)(3)$ :

$$
H m=V m(\delta A-\delta B) 2 \psi A \psi B \quad \text { or } \quad \triangle H m=R T \psi A \psi B \chi A B
$$

where: $V m$-volume of the mixture, $\delta A, \delta B$ - solubility parameters of the components calculated as the square root of the cohesion energy density, volumetric contributions of the components, parameter characterizing the interactions of the components which can be defined as (4):

$$
\chi A B=(V r / R T)^{*}(\delta A-\delta B)^{2}
$$

To fulfill the thermodynamic condition of miscibility, the critical parameters of the mixture are defined. Exceeding theses parameters always leads to the phases separation. A critical interaction parameter is also directly connected with the critical temperature which cannot be exceeded if a homogenous mixture is to be obtained. It can be said that the total miscibility occurs when $\beta=(\delta 1-\delta 2) 2<=0,7-1 \mathrm{MJ} / \mathrm{m}$, partial miscibility - when: $\beta=1-3 \mathrm{MJ} / \mathrm{m}^{2}$ and for $\beta>=3 \mathrm{MJ} / \mathrm{m}^{2}$. we speak of no spontaneous miscibility [7].

The stability of the dispersion of the components in the polymeric matrix (no matter if they are miscible or not ) can be explained by the increase of the system entropy which depends on diffusion rate of the components. In polymers, due to high viscosity, diffusion progresses rather slowly.

Most polymers are thermodynamically non--miscible. That is why after a mechanical mixing the microhetherogenic systems are formed which means that in the matrix (continuous medium) another phase in the form of tiny particles (domains) is dispersed. The dimensions and the shapes of the domains are not stable. In the molten state if there are no shear stresses, the domains tend to separate from the matrix. Such phenomenon occurs in the polymer processing when the material is cooled. Thus the non-miscible polymeric systems are very strongly influenced by the following processing cycles. In order to obtain a good polymeric material care should be taken not only for a good dispersion of one of the components in the other one but also for a good stability of the dispersion degree.

One of the methods to stabilize the phase structure is the improvement of the molecular interaction which can be obtained by:

- preparing polymer compositions from interphase active micromolecular components, 
- $\quad$ adding extra polymeric additive impeding the mass exchange in the molten system,

- creating chemical interphase links in the technological process,

- $\quad$ creating mutually penetrating crosslinked structures [7, 9].

Di- and triblock copolymers have found application as the compatibilizers where every block has a good miscibility with the other component of the system. This leads to the increase of the mutual penetration of the two phases which become a component of the stable intermediate phase. Another method of obtaining the compatibilizers is the partial grafting of one component on the other which often takes place during mixing (in-situ). Chemical exchange reaction between the macromolecules of various polymers being the components of the mixture can lead to obtaining statistical multiblock copolymers. A kind of this modification is a partial reaction between the endings of different macromolecules (the so called endlinking). An example of stabilizing the phase structure as a result of molecular interaction are the block copolymers [9-14].

As a result of chemical links between the copolymer segments and microphases produced from them, polymer systems of high stability in the repeated processing cycles are formed. The degree of phase separation and the domain size depends first of all on the kind, length and the contribution of the individual segments in the copolymer and is little dependent on the technological conditions of cooling or melting. In this work two materials were selected for preparing a physical mixture: polylactide (PLA) and polypropylene (PP). The purpose was the attempt to make the mixtures of such proportions of the components that either PLA or PP was the matrix. A particular case was the mixture of the 50/50 PLA/PP proportions. The next important task was the effect of multiple processing on the strength of the obtained material [10-16].

Further physical modification leads to the change of the mixture's structure, molecular interaction and dispersion degree $[3,4]$. The properties of such composition would depend on the content of the components, the way of its preparation and mutual interaction of the components [5, 6]. As was mentioned above, in the present paper two polymeric components were selected for preparing the mixture: polylactide and polypropylene.

Polylactide is an entirely biodegradable thermoplastic linear polyester. It can be processed using typical technologies: injection, extrusion, thermoforming or extrusion blow molding [16,20]. It is produced by means of polycondensation of lactide acid or cyclic lactides. Lactide acid is an intermediate product which is in turn obtained in the bacterial fermentation of starch derived usually from corn or in the course of milk processing [10-23]. PLA is used in the packaging industry, medicine and agriculture [10-18]. It can be recycled and processed many times [21]. It is often called "double green" because it is both biodegradable and obtained from the renewable raw materials, thus it is considered as the polymer of XXI century. Its contribution to all known biodegradable polymers is about $40 \%$.

The properties of this polymer are similar to the ones of polystyrene as it is rigid, its glass transition temperature is $57^{\circ} \mathrm{C}$ and the flow temperature is $170-180^{\circ} \mathrm{C}$. It has a good transparency and shine. It exhibits good strength properties and low elongation at break (3-4\%) in a tensile test. Its disadvantage is easy water sorption which makes drying before processing necessary.

$[14,19]$. Another disadvantage is its rather high density $\left(1.25 \mathrm{~g} / \mathrm{cm}^{3}\right)$ compared to PP and PS. High polarity of PLA does not let for a good adhesion to non-polar polymers (PE, PP) in multilayer structures. Also its thermal resistance and oxygen barrier are worse in compared with PET. In the optimized condition of compostability the bottles of PLA are decomposed within 75-80 days [15-16]. Figure 1 presents the chemical formula of polylactide.

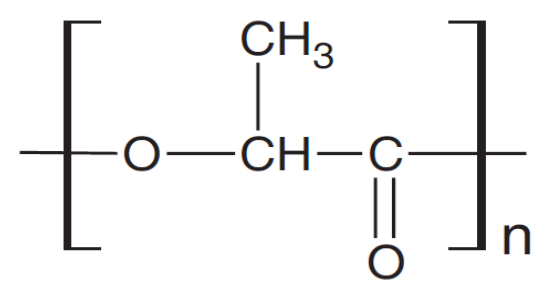

Figure. 1. Chemical formula of polylactide .

This material exhibits good ability of resorption, thanks to which it is used in many fields, among others in packaging industry and medicine. For many years it has been the object of thorough research and its popularity is constantly growing. It is very often compared to PET in terms of 
mechanical strength, flexibility and barrier properties. Primarily the application of PLA was limited to the biomedical area due to high cost and rather small molecular weight. Nowadays it is possible to manufacture PLA of high molecular weight, good mechanical, thermal and processing properties in an economic way. PLA is used in many branches of the industry, among others for manufacturing double oriented films, paper lamination, thermoformable films, injection and producing weldable layer in multilayer systems. The products of PLA are used as containers, packaging films and gardening films, disposable products, bottles, fibers, fabrics and elements of household utilities. They are also used in medicine as bioresorboval implants and threads, clamps, clips, surgery masks, dressings, compresses, medical staff clothes, pharmacy products and the personal hygienic products. PLA is an aliphatic polyester, which has good chemical and physical properties. It is rigid and brittle very much alike polystyrene and it is easy to manufacture items by means of typical processing technologies. The disadvantages of PLA are: high humidity absorption in the granulated form, poor barrier properties (especially in case of packaging )for $\mathrm{O} 2$ and $\mathrm{CO} 2$, the possibility of partial degradation during processing, disadvantageous properties in the molten state and low molecular weight. Due to high polarity, a good adhesion to non-polar polymers like PE and PP is not possible. It can be, however, many times processed and nowadays its contribution to all biodegradable polymers is approximately $40 \%$ [23].

The second material used for preparing the mixture was polypropylene, the polymer belonging to polyolefin group. It is obtained in a low-pressure polymerization of propylene.

Polypropylene as well as polyethylene is the most frequently used polymer. It can be processed with all technologies and finds an application in almost every area of household and engineering. Its properties are well known.

Polypropylene is a hydrocarbon thermoplastic polymer which means that at high temperature it becomes very flexible and after cooling it retrieves its primary rigidity. This polymer is obtained from propylene polymerization with the presence of metallographic catalyzers. The reaction takes place at the temperature $100^{\circ} \mathrm{C}$ in the environment of liquid aliphatic hydrocarbons. Depending on the kind of the catalyzer and on the polymerization condition, the following polymers of various spatial structures can be obtained (fig. 2) [14, 22-26]:

- isotactic polypropylene which has the best mechanical properties and the highest thermal resistance of all kinds of polypropylenes due to the orderly spatial structure and high crystallinity.

- atactic polypropylene of non-orderly spatial structure, possessing the properties similar to those of non-vulcanized rubber,

- $\quad$ syndiotactic polypropylene which exhibits the intermediate properties between the isotactic and atactic ones.

Isotactic polypropylene (i-PP)
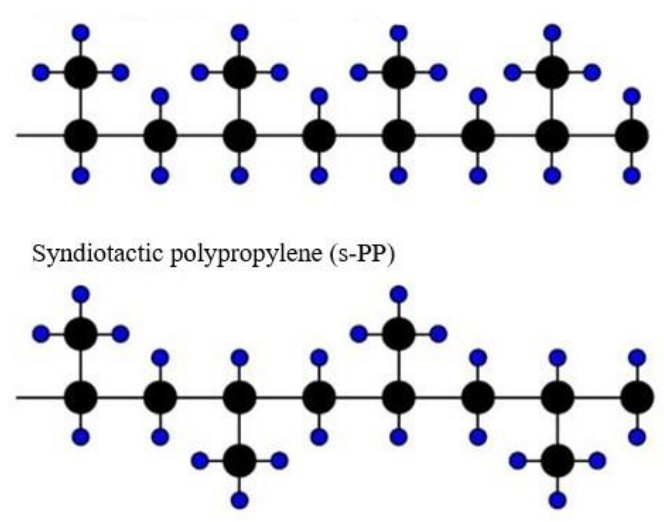

Atactic polypropylene (a-PP)

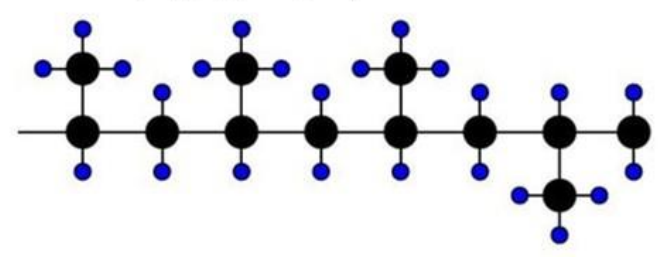


Polypropylene is one of the lightest polymers; its density is about $0.92 \mathrm{~g} / \mathrm{cm} 3$. In natural state this material is semi-transparent and odorless. Mechanical and thermal properties improve when the degree of crystallinity increases. Impact strength is high and only the notch on the specimens lowers it substantially. In order to improve the mechanical properties and the thermal resistance, some fillers like glass fiber, talc, chalk at the amount of $10-40 \%$ are introduced [12].

The chemical resistance of polypropylene is very high. At the room temperature it is practically resistant to acids, lyes, salts and organic solvents. Its resistance to environmental factors is poorer than the one of polyethylene and that is why it undergoes aging process faster than polyethylene.

Physiological indifference and the ability to function constantly at the temperatures higher than $100^{\circ} \mathrm{C}$ allow for its application as packaging for pharmaceutics and the elements of medical equipment. Due to its high chemical resistance it is used for manufacturing chemical equipment and containers. for storing aggressive media. Good mechanical and thermal properties of polypropylene make it useful as en engineering material in industry for machine parts, housings and protective elements. Good electric properties accompanied with other advantageous properties make it a good material in electric industry.

In order to improve its properties some additives and fillers are introduced. Their main purpose is:

- flammability reduction,

- preventing oxidation of the material during processing,

- stabilizing acids and metallic molecules remaining in the material

after the polymerization,

lowering degradation resulting from sunrays and UV radiation,

giving desired color,

- improving processing properties,

- modifying physical properties,

- preventing electrostatic charge,

- $\quad$ lowering the price.

Apart from the above, polypropylene is mixed with the other polymers including biodegradable polymers which are mainly represented by PLA, in this way creating new materials of unique properties.

The purpose of the this paper is the preparation of PLA/PP mixtures and the analysis of the influence of multiple processing on the mechanical strength of the composition.

\section{Materials tested.}

\section{Polylactide (PLA)}

Polylactide manufactured by NatureWorks (USA) under the commercial name Ingeo Biopolymer 3251D intended for injection molding was used in this paper. Its features are good transparency, good oxygen barrier and little post-processing shrink. Before processing, this material must be dried to decrease its humidity to $0.01 \%$ because the content of water effects negatively its final quality. Its melt flow index $\operatorname{MFR}\left(210^{\circ} \mathrm{C}, 2.16 \mathrm{~kg}\right)$ is in the range $70-85 \mathrm{~g} / 10 \mathrm{~min}$ [27].

\section{Polypropylene (PP)}

Polypropylene manufactured by Brasken (Brasil) under the commercial name H734-52RNA intended for injection molding was used in this work. Its features are low shrink and high dimensional stability. It is used mainly for food and cosmetics packaging, household and office utilities. Its melt flow index $\operatorname{MFR}\left(230^{\circ} \mathrm{C} / 2.16 \mathrm{~kg}\right)$ is $52 \mathrm{~g} / 10 \mathrm{~min}$ [28].

\section{Preparing the specimens to be tested.}

The mixtures were obtained by means of a drum mixer. The following ratios of the components in the mixtures were applied:

1. $100 \%$ PP (pure PP),

2. $75 \%$ parts by weight $P P+25 \%$ parts by weight PLA,

3. $50 \%$ parts by weight $\mathrm{PP}+50 \%$ parts by weight PLA,

4. $25 \%$ parts by weight $\mathrm{PP}+75 \%$ parts by weight PLA, 


\section{5. $100 \%$ PLA (pure PLA)}

The specimens for strength tensile tests were paddle-shaped according to standard ISO 527-2 [29]. They were injection molded with the screw injection machine equipped with a mould with exchangeable cavities. The peripherial deviceswere: thermostat, electronic scales, dryer KC100/200 and a grinder for grinding polymers. Out of each series of injection molded specimens some were strength tested and the others were grinded and processed again.

The mechanical strength tests were performed on the tester Fu1000e by Heckert (Germany) with the force sensor range $10 \mathrm{kN}$. The specimens were statically stretched at the velocity of the clamp 2 $\mathrm{mm} / \mathrm{min}$ in accordance with the corresponding standards. Tensile stress and the strain at elongation of the specimens were recorded.

\section{Experimental part and the results.}

In all the figures presenting static tensile curves roman numbers denote multiplicity of processing. In figure 1 the tensile curves for polypropylene corresponding to the following processing cycles are shown; the results are presented in table 1 . The effect of multiple processing on the properties of polypropylene is minor. All curves are very much alike (fig. 3), the same concerns maximum stress and the corresponding strain. Pure polypropylene can be multiple processed practically without any harm to its mechanical properties.

Table 1. Mechanical properties versus multiplicity of processing for pure polypropylene.

\begin{tabular}{cccccc}
\hline cycle number & I & II & III & IV & V \\
\hline maximum stress $\sigma \quad[\mathrm{MPa}]$ & 36,6 & 34,4 & 34,4 & 34,4 & 34,4 \\
\hline $\begin{array}{c}\text { strain } \varepsilon[1] \text { corresponding to } \\
\text { maximum stress }\end{array}$ & 0,15 & 0,15 & 0,16 & 0,15 & 0,14 \\
\hline
\end{tabular}

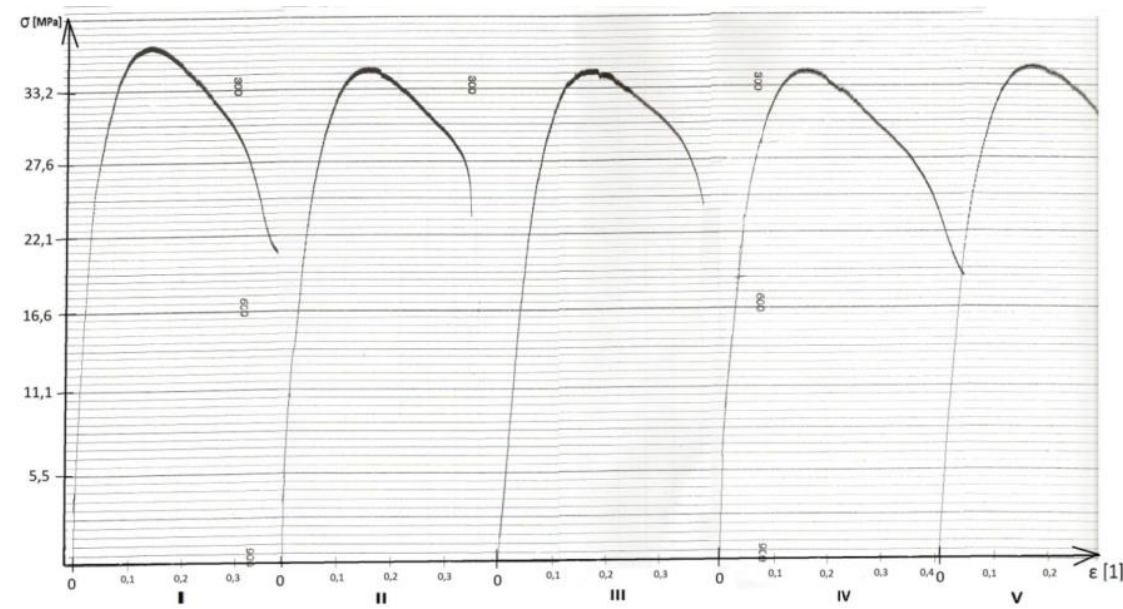

Figure 3. Static tensile curves for pure polypropylene depending on the multiplicity of processing.

In figure 4 static tensile curves for pure polylactide are presented. This material is rather brittle which can be seen from the character of the plots. In table 2 , the results are presented. 


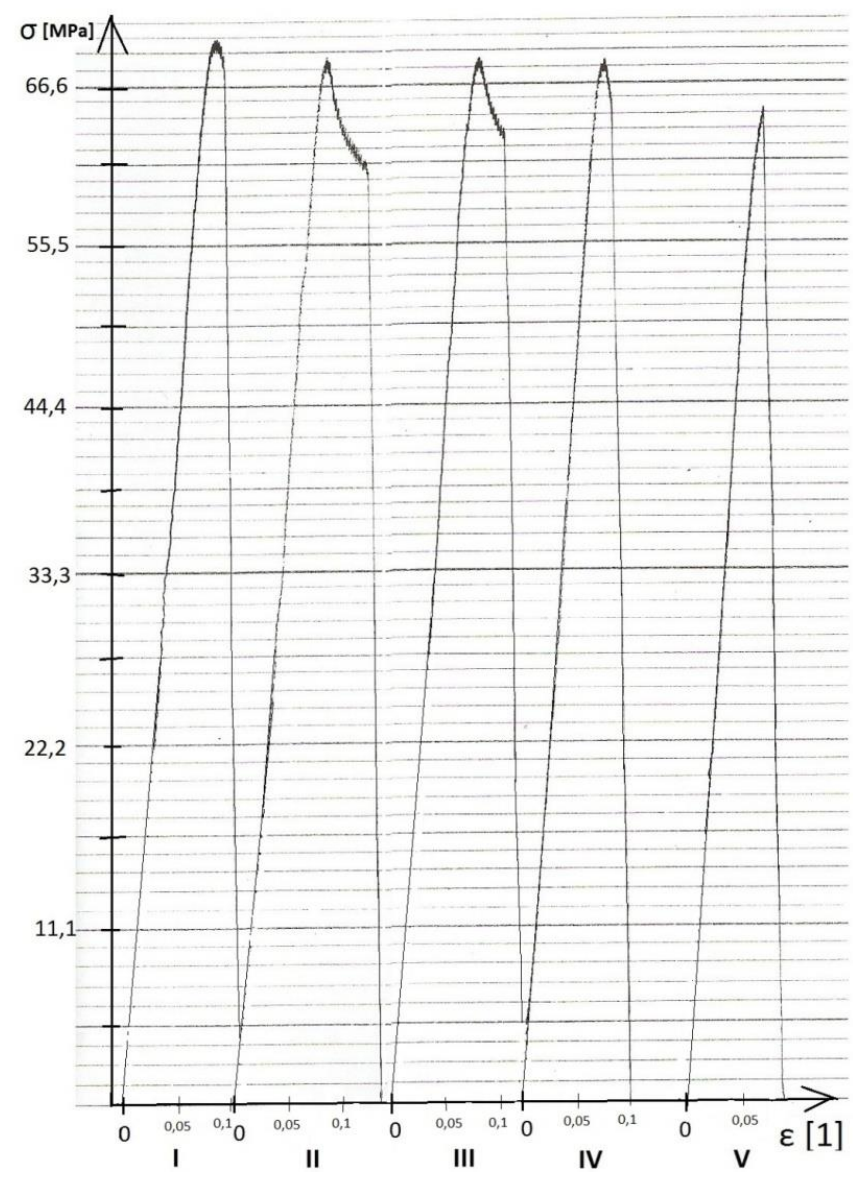

Figure 4. Static tensile curves for pure polylactide depending on the multiplicity of processing.

Table 2. Mechanical properties versus multiplicity of processing for pure polylactide.

\begin{tabular}{cccccc}
\hline cycle number & I & II & III & IV & V \\
\hline maximum stress $\sigma$ [MPa] & 68,8 & 67,7 & 67,7 & 67,7 & 64,4 \\
\hline $\begin{array}{c}\text { strain } \varepsilon[1] \text { corresponding to } \\
\text { maximum stress }\end{array}$ & 0,08 & 0,07 & 0,08 & 0,06 & 0,07 \\
\hline
\end{tabular}

The obtained results show that polylactide is a definitely stronger material than polypropylene . Its strength is within the range 64-68 MPa while for polypropylene it is within 34-36 $\mathrm{MPa}$. It can be seen that qualitatively these are two different materials of different specific mass and different behavior in tensile static test.

In figures 5, 6, 7 the results for the following ratios of the components are shown. Thus at first the strength tests were performed for the mixture of $25 \% \mathrm{PLA}+75 \% \mathrm{PP}$. In this case polypropylene was a matrix in which polylactide was dispersed.

In figure 5 the tensile curves are presented. The material behaved almost like a pure PP. Also its strength did not change much; only in case of the first processing the strength reached the level of $42 \mathrm{MPa}$. The multiplicity of processing also did not essentially effect the strength which dropped only a little. Only the strain corresponding to maximum strength reached half of the value for pure PP. The results are shown in table 3. 


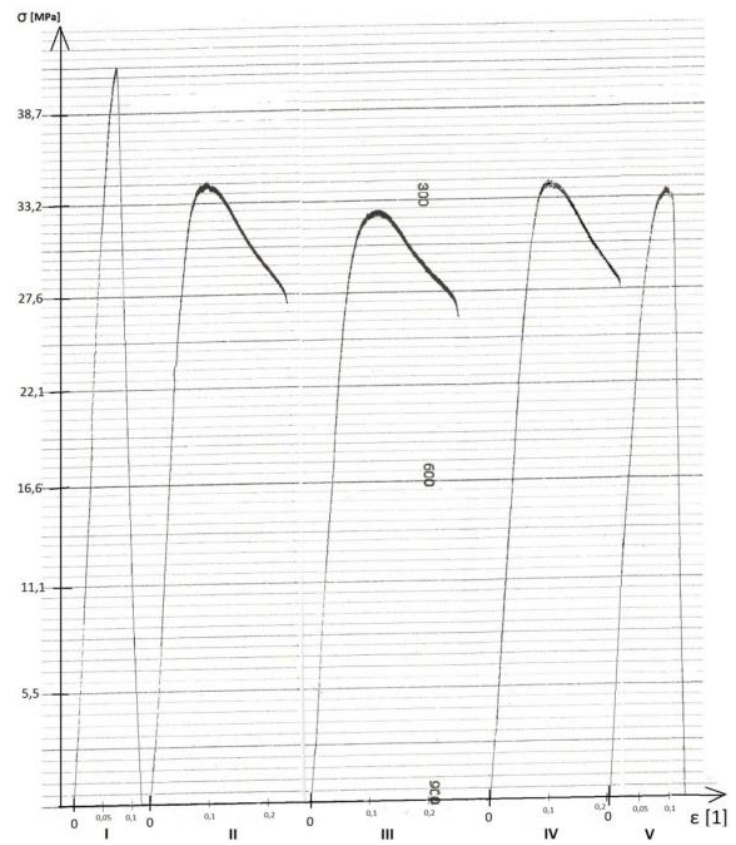

Figure 5. Static tensile curves for the mixture 25\% PLA + 75\% PP depending on the multiplicity of processing.

Table 3. Mechanical properties versus multiplicity of processing for the mixture $25 \%$ PLA $+75 \%$ PP.

\begin{tabular}{cccccc}
\hline cycle number & I & II & III & IV & V \\
\hline maximum stress $\sigma \quad[\mathrm{MPa}]$ & 42,0 & 34,4 & 32,2 & 34,4 & 33,8 \\
\hline $\begin{array}{c}\text { strain } \varepsilon[1] \text { corresponding to } \\
\text { maximum stress }\end{array}$ & 0,08 & 0,09 & 0,09 & 0,08 & 0,09 \\
\hline
\end{tabular}

In case of the next mixture $(50 \% \mathrm{PLA}+50 \% \mathrm{PP})$ the influence of PP upon the mechanical behavior can be clearly seen. The character of the tensile curves as well as the level of the maximum stress (higher than in the last case) make the mixture alike pure PP (fig. 6). In table 4 the results are presented. The strength is a little higher than in the previous case (25\%PLA $+75 \% \mathrm{PP})$. Also, similarly to the previous case, the essential drop of strength occurs only after the second processing. After the next ones the maximum strength remains almost at the same level which also concerns the corresponding strain.

Table 4. Mechanical properties versus multiplicity of processing for the mixture 50\%PLA + 50\%PP.

\begin{tabular}{cccccc}
\hline cycle number & I & II & III & IV & V \\
\hline maximum stress $\sigma \quad[\mathrm{MPa}]$ & 43,3 & 38,3 & 38,3 & 38,8 & 38,3 \\
\hline $\begin{array}{c}\text { strain } \varepsilon[1] \text { corresponding to } \\
\text { maximum stress }\end{array}$ & 0,06 & 0,05 & 0,06 & 0,07 & 0,06 \\
\hline
\end{tabular}




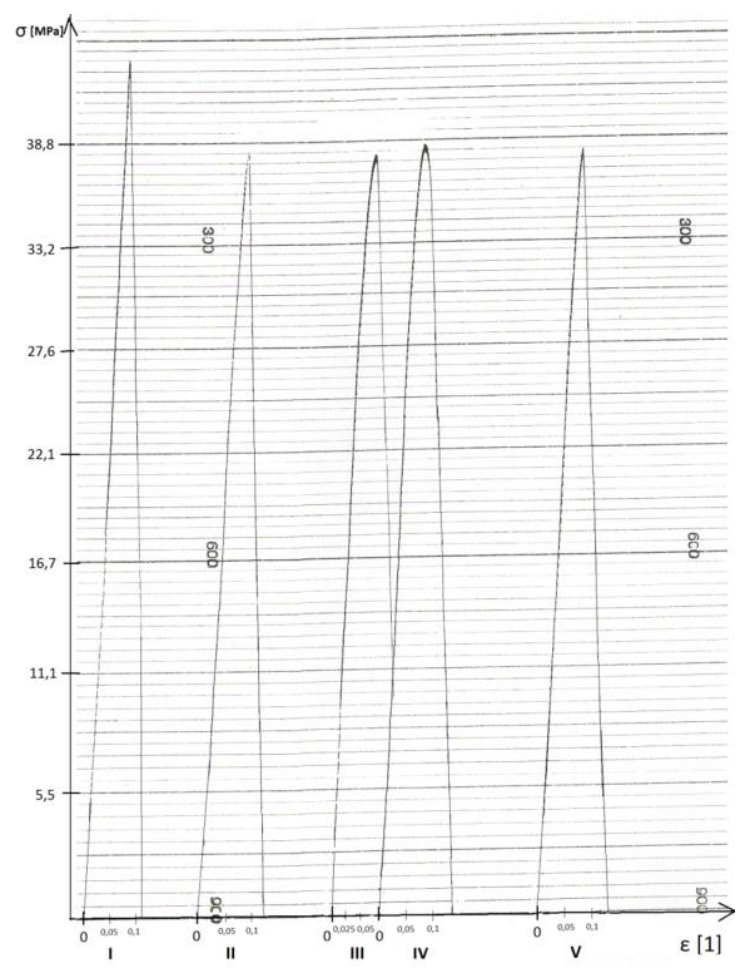

Figure 6. Static tensile curves for the mixture 50\% PLA + 50\% PP depending on the multiplicity of processing.

The last tested material was a mixture of $75 \%$ PLA $+25 \%$ PP. In this case polylactide was a matrix in which polypropylene was dispersed. In figure 7 the static tensile curves are shown. The material behaves in a way similar to the behavior of pure PLA, its strength is, however, higher (table 5). Here polypropylene acts as the reinforcement of the polylactide. Strain corresponding to the maximum stress is at the level similar to other mixtures. Also, as is the case of other mixtures, only the second processing causes essential drop of its value. The next processing cycles do not bring about changes of its value.

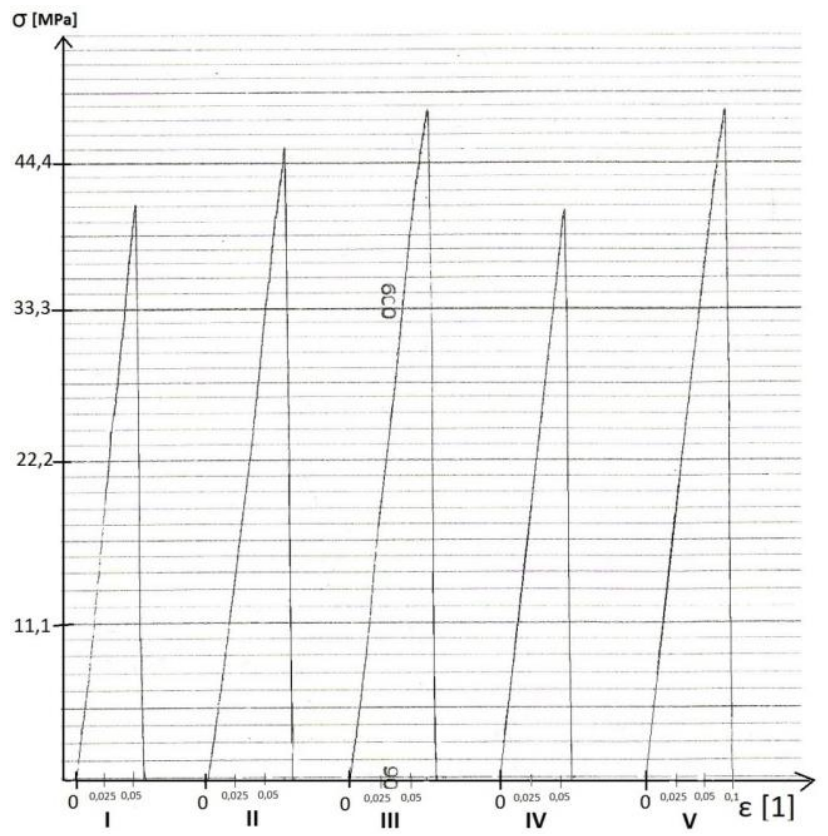

Figure 7. Static tensile curves for the mixture 75\% PLA + 25\% PP depending on the multiplicity of processing. 
Table 5. Mechanical properties versus multiplicity of processing for the mixture 75\% PLA + 25\% PP.

\begin{tabular}{cccccc}
\hline cycle number & I & II & III & IV & V \\
\hline maximum stress $\sigma \quad[\mathrm{MPa}]$ & 41,1 & 45,5 & 47,7 & 41,1 & 47,7 \\
\hline $\begin{array}{c}\text { strain } \varepsilon[1] \text { corresponding to } \\
\text { maximum stress }\end{array}$ & 0,05 & 0,06 & 0,06 & 0,05 & 0,07 \\
\hline
\end{tabular}

\section{Conclusions}

The tests show that it is possible to make mixtures of two very different polymers like polylactide and polypropylene. The particularly interesting case is the mixture of the 1:1 ratio of the components. Further research might bring interesting results because in this case it is not possible to determine which material is the matrix and which is the filler. The effect of the multiplicity of processing upon the strength properties is comparable for all tested materials, both for the pure ones (pure PLA and pure PP) and for the mixtures of different ratios of the components. All tested materials exhibited the best properties after the first processing. Then, following the next cycles, those properties decreased. This phenomenon is very common as each processing cycle causes certain degradation of the material. The drop of the mechanical parameters is, however, not dramatic which means that the recycled materials can be accepted for many applications.

\section{Funding}

This research was funded by using the statutory subsidy of the Faculty of Production Engineering of the Warsaw University of Technology in 2019.

\section{Conflicts of Interest}

The authors declare no conflict of interest.

\section{References}

1. Garbarski J., Non-metallic materials and composites, Warsaw University of Technology Publishing House, Warsaw 2001.

2. Rabek J.F., Modern knowledge about polymers, PWN Scientific Publisher, Warsaw 2008.

3. Ngai, K. L., Valenti, S., Capaccioli, S. (2019). Molecular dynamic in binary mixtures and polymer blends with large difference in glass transition temperatures of the two components: A critical review. Journal of Non-Crystalline Solids, 2019, 119573. https://doi.org/10.1016/j.jnoncrysol.2019.119573

4. Hou, J., Han, M., Fuseni, A., AlSofi, A. A New Approach to Determine the Individual Chemical Concentrations in Surfactant-polymer Mixtures. In 79th EAGE Conference and Exhibition 2017.

5. K. L. Ngai,, S. Capaccioli, and, C. M. Roland. Comment on A Molecular Dynamics Simulation Study of Relaxation Processes in the Dynamical Fast Component of Miscible Polymer Blends . Macromolecules 2006, 39 (24) , 8543-8543. DOI: 10.1021/ma061279s

6. Malinowski, R., Moraczewski, K., Raszkowska-Kaczor, A. (2020). Studies on the Uncrosslinked Fraction of PLA/PBAT Blends Modified by Electron Radiation. Materials, 2020, 13, (5), 1068.

7. Nicholson, J. The chemistry of polymers. Royal Society of Chemistry.2017.

8. Fabijanski, M., Garbarski, J. The effect of multiple processing on the strength of polylactide/polypropylene mixture. Przemysl Chemiczny, 2017, 96, 3 , 567-570, DOI:10.15199/62.2017.3.16.

9. Srikanth Pilla, Handbook of Bioplastics and Biocomposites Engineering Applications. 373-396, ISBN 978-0-470-62607-8, WILEY 2012.

10. Fabijanski, M. Mechanical strength and flammability of polylactide. Przemysl Chemiczny, 2019, 98, 4, 556-558, DOI:10.15199/62.2019.4.8

11. Fabijanski, M. Multiple processing of polylactide. Przemysl Chemiczny, 2016, 95(4), 874-876. DOI:10.15199/62.2016.4.33.

12. Chmielewski T. , Hudycz M., Krajewski A., Sałaciński T. , Skowrońska B., Świercz R. Structure Investigation of Titanium Metallization Coating Deposited onto AlN Ceramics Substrate by Means of Friction Surfacing Process, Coatings, 2019, 9(12), 845, https://doi.org/10.3390/coatings9120845.

13. Fabijański, M., Garbarski, J. The application of neural networks to property optimization of polymer compositions. Advances in Manufacturing Science and Technology, 2016, 40, 4 . 
14. Jeziórska R., Kijeński J., Błędzki A.K. (red.), Recovery and recycling of polymeric materials, PWN, Warsaw 2011.

15. Soroczyński, A. Haratym, R. Biernacki, R. The Role of Recycled Ceramic Material Obtained from the Ceramic Layered Moulds Used in the Investment Casting, Archives of Foundry Engineering, 2019, 1, 71-74, DOI: 10.24425/afe.2018.125194

16. Sionkowska A, Current research on the blends of natural and synthetic polymers as new biomaterials: Review. Progress in Polymer Science, 2011, 36: 1254 -1276.

17. Huda, MS, Drzal, LT, Misra, M. i Mohanty, AK, J. Appl. Polym. Sci., 2006, 102, 4856. doi: 10,1002 / app.24829.

18. Foltynowicz Z., Jakubiak P., Polimery 2002, 47, 769.

19. Sen-lin Yang, Zhi-Hua Wu, Wei Yang, Ming-Bo Yang, Polym. Test., 2008, 27, (8), 957.

20. Huda, MS, Drzal, LT, Misra, M. i Mohanty, AK,. J. Appl. Polym. Sci., 2006, 102, 4856. doi: 10,1002 / app.24829.

21. Yang Y, Murakami M, Hamada H, J. Polym. Environ., 2012, 20 (4), 1124, DOI: 10.1007/s10924-012-0565-8.

22. Arao, Y., Fujiura, T., Itani, S. and Tanaka, T. (2015) Strength Improvement in Injection-Molded Jute-Fiber-Reinforced Polylactide Green-Composites. Composites Part B: Engineering, 68, 200-206.http://dx.doi.org/10.1016/j.compositesb.2014.08.032.

23. Ru Liu, Shupin Luo, Jinzhen Cao, Yao Peng, Journal: Composites Part A: Applied Science and Manufacturing, 2013, 51, 33, doi: 10.1016/j.compositesa.2013.03.019.

24. Yang Y, Murakami M, Hamada H., Journal: Journal of Polymers and the Environment, 2012,20 (4), 1124, DOI: 10.1007/s10924-012-0565-8.

25. Arao Y, Fujiura T, Itani S., Tanaka T., Journal: Composites Part B: Engineering, 2015, 68, 200, doi: 10.1016/j.compositesb.2014.08.032.

26. Pilarek M., Grabowska I., Senderek I., Wojasiński M., Janicka J., JanczykIlach K., Ciach T., Liquid perfluorochemical-supported hybrid cell culture system for proliferation of chondrocytes on fibrous polylactide scaffolds, Bioprocess Biosystems Engineering, 2014, 37, 1707-1715, DOI:10.1007/s00449-014-1143-3.

27. Ingeo ${ }^{\mathrm{TM}}$ Biopolymer 3251D Technical Data Sheet, NatureWorks LLC

28. BRASKEM H734-52RNA Technical Data Sheet, BRASKEM.

29. ISO 527-2: 2012 